\title{
Phenolic profile in the quality control of walnut (Juglans regia L.) leaves
}

\author{
Joana S. Amaral ${ }^{\text {a,b }}$, Rosa M. Seabra ${ }^{\text {a,* }}$, Paula B. Andrade a ${ }^{\text {, Patrícia Valentão a }}$, \\ José A. Pereira $^{\mathrm{c}}$, Federico Ferreres ${ }^{\mathrm{d}}$ \\ ${ }^{a}$ REQUIMTE, Serviço de Farmacognosia, Faculdade de Farmácia, Universidade do Porto, R. Aníbal Cunha, 164, 4050-047 Porto, Portugal \\ ${ }^{\mathrm{b}}$ Escola Superior de Tecnologia e de Gestão, Instituto Politécnico de Bragança, Quinta de Sta. Apolónia, Apartado 134, 5301-857 Bragança, Portugal \\ ${ }^{\mathrm{c}}$ Escola Superior Agrária, Instituto Politécnico de Bragança, Quinta de Sta. Apolónia, Apartado 134, 5301-857 Bragança, Portugal \\ ${ }^{\mathrm{d}}$ Departament of Science and Technology, Research Group on Quality, Safety and Bioactivity of Plant Foods, CEBAS-CSIC \\ P.O. Box 164, E-30100 Espinardo, Murcia, Spain
}

Received 10 November 2003; received in revised form 12 January 2004; accepted 12 January 2004

\begin{abstract}
Qualitative and quantitative determinations of phenolic compounds were carried out on walnut leaves samples from six different cultivars, with the same agricultural, geographical and climatic conditions. The evolution of major phenolic compounds amounts was monitored from May to September. Two extractive procedures were assayed and best results were obtained using acidified water and a solid phase extraction column purification step. Qualitative analysis was performed by HPLC-DAD/MS and, in all samples, seven phenolic compounds were identified (3-caffeoylquinic, 3-p-coumaroylquinic and 4-p-coumaroylquinic acids, quercetin 3-galactoside, quercetin 3-arabinoside, quercetin 3-xyloside, quercetin 3-rhamnoside) and two other partially identified phenolics (quercetin 3-pentoside and kaempferol 3-pentoside derivatives) were also detected. Quantification of phenolic compounds was performed by HPLC-DAD, which revealed that quercetin 3-galactoside was always the major compound while 4-p-coumaroylquinic acid was the minor one. The highest content of phenolics was found in May and July.
\end{abstract}

(c) 2004 Elsevier Ltd. All rights reserved.

Keywords: Juglans regia L.; Walnut leaf; Phenolic compounds; HPLC-DAD; HPLC/DAD/MS-ESI

\section{Introduction}

Plants can be used in the food industry for their organoleptic and nutritional qualities, as sources of antioxidants to preserve food quality $(\mathrm{Chu}, \mathrm{Sun}, \mathrm{Wu}, \&$ Liu, 2002), and also for medicinal purposes, since medicinal herbs are still a major source of healthcare and disease prevention for a great part of the world's population. Walnut (Juglans regia L.) leaf has been widely used in folk medicine for treatment of venous insufficiency and haemorrhoidal symptomatology, and for its antidiarrheic, antihelmintic, depurative and astringent properties (Bruneton, 1993; Van Hellemont, 1986;

\footnotetext{
${ }^{*}$ Corresponding author. Tel.: +351-222-078-934; fax: +351-222-003977.

E-mail address: rseabra@ff.up.pt (R.M. Seabra).
}

Wichtl \& Anton, 1999). Keratolytic, antifungal, hypoglycaemic, hypotensive, anti-scrofulous and sedative activities have also been described (Gîrzu et al., 1998; Valnet, 1992).

Juglone (5-hydroxy-1,4-naphthoquinone) is the characteristic compound of Juglans spp., which is reported to occur in fresh walnut leaves (Bruneton, 1993; Gîrzu et al., 1998; Wichtl \& Anton, 1999). Nevertheless, because of polymerization phenomena, juglone is reported to occur in the drug (dry leaves) only in vestigial amounts (Wichtl \& Anton, 1999), which means that the compound is not suitable for use in the quality control of the dry plant. Besides these, other phenolics, namely phenolic acids and flavonoids, have been reported in walnut leaves (Wichtl \& Anton, 1999). The chemical characterization of the drug is described in some pharmacopoeias, by TLC detection of quercetin 3-galacto- 
side and quercetin 3-rhamnoside (Pharmacopée Française, 1989). However, due to their ubiquity in nature, these flavonoids do not guarantee the plant authenticity and, more identified compounds would be more useful for characterisation.

In Portugal, as in some other European countries, dry walnut leaves are still largely used as an infusion. Because flavonoids and phenolic acids have already been successfully applied in the quality control of several foodstuffs (Andrade, Ferreres, \& Amaral, 1997; Andrade, Leitão, Seabra, Oliveira, \& Ferreira, 1997; Areias, Valentão, Andrade, Ferreres, \& Seabra, 2001; Ramos et al., 1999; Silva et al., 2000), in the present work phenolics of walnut leaves have been studied by HPLC/ DAD/MS/MS - ESI. A useful methodology for routine quality control, based on HPLC-DAD quantification of major phenolics was developed and applied to six different cultivars growing under the same agricultural, geographical and climatic conditions. The evolution of phenolic compounds from May to September was also monitored.

\section{Materials and methods}

\subsection{Chemicals}

The standards were purchased from Sigma (St. Louis, MO, USA) and Extrasynthése (Genay, France). Methanol and hydrochloric and formic acids were obtained from Merck (Darmstadt, Germany). The water was treated in a Milli-Q water purification system (Millipore, Bedford, MA, USA).

\subsection{Samples}

Studies were carried out on walnut leaves from six cultivars (Franquette, Marbot, Mayette, Mellanaise, Lara and Parisienne) grown in Portugal. Fresh leaves were collected at "Quinta de Santa Apolónia", an orchard in Bragança, in the northeastern region of Portugal $\left(6^{\circ} 46^{\prime} \mathrm{W}, 41^{\circ} 49^{\prime} \mathrm{N}, 670 \mathrm{~m}\right.$ a.s.1.). The orchard has a planting density of $7 \times 7 \mathrm{~m}$, with all trees being more than eighteen years old. They are pruned when necessary and receive organic fertilization, but no phytosanitary treatments are applied. The surrounding soil is tilled to control infestations and irrigated in Summer (July and August). Fresh samples of all cultivars were collected on the same day, from May to September of 2002, at the end of each month. For each sample, about $100 \mathrm{~g}$ of leaves were manually collected from the middle third of branches exposed to sunlight, dried in a stove at $30{ }^{\circ} \mathrm{C}$ for five days and stored in paper bags in order to protect them from light. Just before phenolic extraction, each sample was powdered to a maximum particle size of $910 \mu \mathrm{m}$.

\subsection{Solid-phase extraction columns}

The ISOLUTE C18 non-end-capped (NEC) Solidphase extraction (SPE) columns $(50-\mu \mathrm{m}$ particle size, 60 A porosity; $10 \mathrm{~g}$ sorbent mass $/ 70 \mathrm{ml}$ reservoir volume) were purchased from International Sorbent Tecnology Ltd. (Mid Glamorgan, UK).

\subsection{Extraction of phenolic compounds}

For analytical purposes, the sample (ca. $0.2 \mathrm{~g}$ ) was thoroughly mixed with methanol until complete extraction of phenols (negative reaction with $\mathrm{NaOH} 20 \%$ ). The extract was then filtered, evaporated to dryness under reduced pressure $\left(40{ }^{\circ} \mathrm{C}\right)$, and redissolved in $3 \mathrm{ml}$ of methanol. A chloroformic extract was also prepared with the same sample: ca. $0.5 \mathrm{~g}$ of plant material was extracted three times with $100 \mathrm{ml}$ of chloroform, with agitation, for $10 \mathrm{~min}$. The extracts were pooled, taken to dryness under reduced pressure $\left(40^{\circ} \mathrm{C}\right)$ and the residue dissolved in $3 \mathrm{ml}$ of methanol.

For quantification purposes, each sample (ca. $0.2 \mathrm{~g}$ ) was thoroughly mixed with acidified water ( $\mathrm{pH} 2$ with $\mathrm{HCl}$ ) until complete extraction of phenolic compounds (negative reaction to $\mathrm{NaOH} \mathrm{20 \% )} \mathrm{and} \mathrm{filtered.} \mathrm{The} \mathrm{fil-}$ trate was passed trough an ISOLUTE C18 (NEC) column, previously preconditioned with $60 \mathrm{ml}$ of methanol, followed by $140 \mathrm{ml}$ of water ( $\mathrm{pH} 2$ with $\mathrm{HCl}$ ). The retained phenolic fraction was eluted with methanol (ca. $75 \mathrm{ml}$ ) and the methanolic extract obtained was filtered, evaporated to dryness under reduced pressure $\left(40{ }^{\circ} \mathrm{C}\right)$ and redissolved in methanol $(3 \mathrm{ml})$.

\subsection{HPLC/DAD/MS/MS for qualitative analysis}

Chromatographic separation was carried out on a reversed-phase LiChroCART column $(250 \times 4 \mathrm{~mm}$, RP18, $5 \mu \mathrm{m}$ particle size; Merck, Darmstadt, Germany) using two solvents: trifluoroacetic acid $(0.1 \%)$ (A) and methanol (B), starting with 30\% methanol and installing a gradient to obtain $50 \% \mathrm{~B}$ at $30 \mathrm{~min}, 70 \% \mathrm{~B}$ at $32 \mathrm{~min}$, $80 \% \mathrm{~B}$ at $33 \mathrm{~min}$ and $80 \% \mathrm{~B}$ at $35 \mathrm{~min}$. The flow rate was

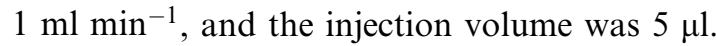

The HPLC system was equipped with a diode array detector (DAD) and mass detector in series (Agilent 1100 Series LC/MSD Trap). It consisted of an Agilent G1312A HPLC binary pump, an Agilent G1313A autosampler, an Agilent G1322A degasser and an Agilent G1315B photo-diode array detector controlled by Agilent software v. A.08.03 (Agilent Technologies, Waldbronn, Germany). Chromatograms were recorded at 280, 320 and $350 \mathrm{~nm}$. The mass detector was an Agilent G2445A Ion-Trap Mass Spectrometer (Agilent Technologies, Waldbronn, Germany) equipped with an electrospray ionisation (ESI) system and controlled by Agilent Software v. 4.0.25. Nitrogen was used as nebu- 
lizing gas at a pressure of 65 psi and the flow was adjusted to $111 \mathrm{~min}^{-1}$. The heated capillary and voltage were maintained at $350{ }^{\circ} \mathrm{C}$ and $4 \mathrm{kV}$, respectively. The full scan mass spectra of the phenolic compounds were measured from $m / z 60$ up to $m / z 800$. Collision-induced fragmentation experiments were performed in the ion trap using helium as the collision gas, with a voltage ramping to 0.3 up to $2 \mathrm{~V}$. Mass spectrometry data were acquired in the negative ionisation mode. $\mathrm{MS}^{2}$ data were acquired in the automatic mode.

\subsection{HPLCIDAD for quantitative analysis}

Chromatographic separation was achieved with an analytical HPLC unit (Gilson), using a reversed-phase Spherisorb ODS2 $(250 \times 4.6 \mathrm{~mm}, 5 \mu \mathrm{m}$ particle size, Merck, Darmstadt, Germany) column. The solvent system used was a gradient of water/formic acid (19:1) (A) and methanol (B), starting with 5\% methanol and installing a gradient to obtain $15 \% \mathrm{~B}$ at $3 \mathrm{~min}, 20 \% \mathrm{~B}$ at 5 $\mathrm{min}, 25 \% \mathrm{~B}$ at $12 \mathrm{~min}, 30 \% \mathrm{~B}$ at $15 \mathrm{~min}, 40 \% \mathrm{~B}$ at $20 \mathrm{~min}$, $45 \% \mathrm{~B}$ at $30 \mathrm{~min}, 50 \% \mathrm{~B}$ at $40 \mathrm{~min}, 70 \% \mathrm{~B} 45 \mathrm{~min}$ and $0 \% \mathrm{~B}$ at $46 \mathrm{~min}$. The flow rate was $1 \mathrm{ml} \mathrm{min}{ }^{-1}$, and the injection volume was $20 \mu \mathrm{l}$. Detection was accomplished with a DAD (Gilson), and chromatograms were recorded at 320 and $350 \mathrm{~nm}$. The retention times for the different identified compounds are shown in Table 1.

Spectral data from all peaks were accumulated in the $200-400 \mathrm{~nm}$ range. Data were processed on a Unipoint ${ }^{\circledR}$ system software (Gilson Medical Electronics, Villiers le Bel, France).

Phenolic compounds quantification was achieved by the absorbance recorded in the chromatograms relative to external standards, with detection at $320 \mathrm{~nm}$ for phenolic acids and at $350 \mathrm{~nm}$ for flavonoids. 3-O-Caffeoylquinic acid was quantified as 5-O-caffeoylquinic acid, 3-p-coumaroylquinic and 4-p-coumaroylquinic acids were quantified as $p$-coumaric acid; the quercetin 3 -pentoside derivative and quercetin 3-xyloside were quantified as quercetin 3-arabinoside. The other compounds were quantified as themselves.

\section{Results and discussion}

The phenolic composition of three extracts of dried walnut leaves obtained using methanol, chloroform and acidified water, was studied. As dried leaves were used, juglone was not detected in any extract, which is in accordance with Wichtl and Anton (1999). Gîrzu et al. (1998) have reported the isolation of juglone from a chloroformic extract of fresh walnut leaves. In the present work it was possible to detect this compound only in the chloroformic extract from a fresh sample (data not shown). Bearing in mind that infusion is traditionally prepared with dry plant and that juglone is not detected in the water extract, a methodology based on phenolic compounds determination seemed to be useful for the quality control of walnut leaves.

With the development of electrospray ionisation mass spectrometry (ESI/MS), it has become technically and economically feasible to analyse polar compounds by liquid chromatography coupled with ESI/MS. As several authors have successfully used HPLC/DAD/MSESI in the identification of phenolic compounds in foodstuffs (Llorach, Gil-Izquierdo, Ferreres, \& TomasBarberan, 2003; Zafrilla, Ferreres, \& Tomas-Barberan, 2001), this technique was applied to walnut leaf in order to identify the highest possible number of compounds.

The UV spectra of the compounds obtained by HPLC/DAD analysis revealed that phenolic acids and flavonoids were the two main groups of compounds in walnut leaf extract. The first group, corresponding to peaks 1, 2, 3 (Fig. 1), presented spectral characteristics of cinnamic acids, with two absorption maxima at 250 and $320 \mathrm{~nm}$. HPLC-MS data provided some interesting information about those compounds. Fragmentation of pseudomolecular ion $[\mathrm{M}-\mathrm{H}]^{-}$at $m / z$ 353.6, found for compound 1 , yielded the ion at $m / z 191.5\left([\mathrm{M}-\mathrm{H}]^{-}-162\right)$, base peak corresponding to quinic acid by the loss of a caffeoyl radical from the pseudomolecular ion. Besides, in the $\mathrm{MS}^{2}$ study, the ion at $m / z 179.5$ was also obtained with an abundance of $35 \%$ which, according to Clifford, Johnston, Knight, and Kuhnert (2003), characterizes 3caffeoylquinic acid. A pseudomolecular ion $[\mathrm{M}-\mathrm{H}]^{-}$at $m / z 337.5$ was found for compound 2. Fragmentation of this ion yielded a base peak at $m / z 163.1$, corresponding to the loss of quinic acid radical, which is in accordance with literature data found for 3-p-coumaroylquinic acid (Clifford et al., 2003). Compound 3 also had a pseudomolecular ion at an identical $\mathrm{m} / \mathrm{z}$ found for compound 2 ; in the $\mathrm{MS}^{2}$ study, the base peak was at $m / z 173.1$. According to Clifford et al. (2003) the compound was identified as 4-p-coumaroylquinic acid.

The second group of compounds, corresponding to peaks 4-9, showed UV spectra characteristic of flavonoids. Pseudomolecular ions $[\mathrm{M}-\mathrm{H}]^{-}$at $\mathrm{m} / z$ 463.4, 433.3, 433.3 and 447.4 were found for peaks 4, 6, 7 and 8 , respectively (Fig. 1). Fragmentation of these ions provided a characteristic $m / z$ at 300.9, a typical mass in the negative mode of the quercetin aglycone. Injection of authentic standards of quercetin 3-galactoside, quercetin 3-arabinoside, quercetin 3-xyloside and quercetin 3rhamnoside confirmed the occurrence of these compounds in walnut leaf extract. Compound 5 had a pseudomolecular ion $[\mathrm{M}-\mathrm{H}]^{-}$at $m / z 433.4$, and fragmentation of this also provided a characteristic $\mathrm{m} / \mathrm{z}$ at 300.9 , suggesting the presence of a pentosyl quercetin derivative.

In peak 9, three compounds with pseudomolecular ions at $\mathrm{m} / \mathrm{z} 417.4,475.4$ and 489.4 were co-eluting in the same order. An Extracted ion chromatogram (EIC), and 


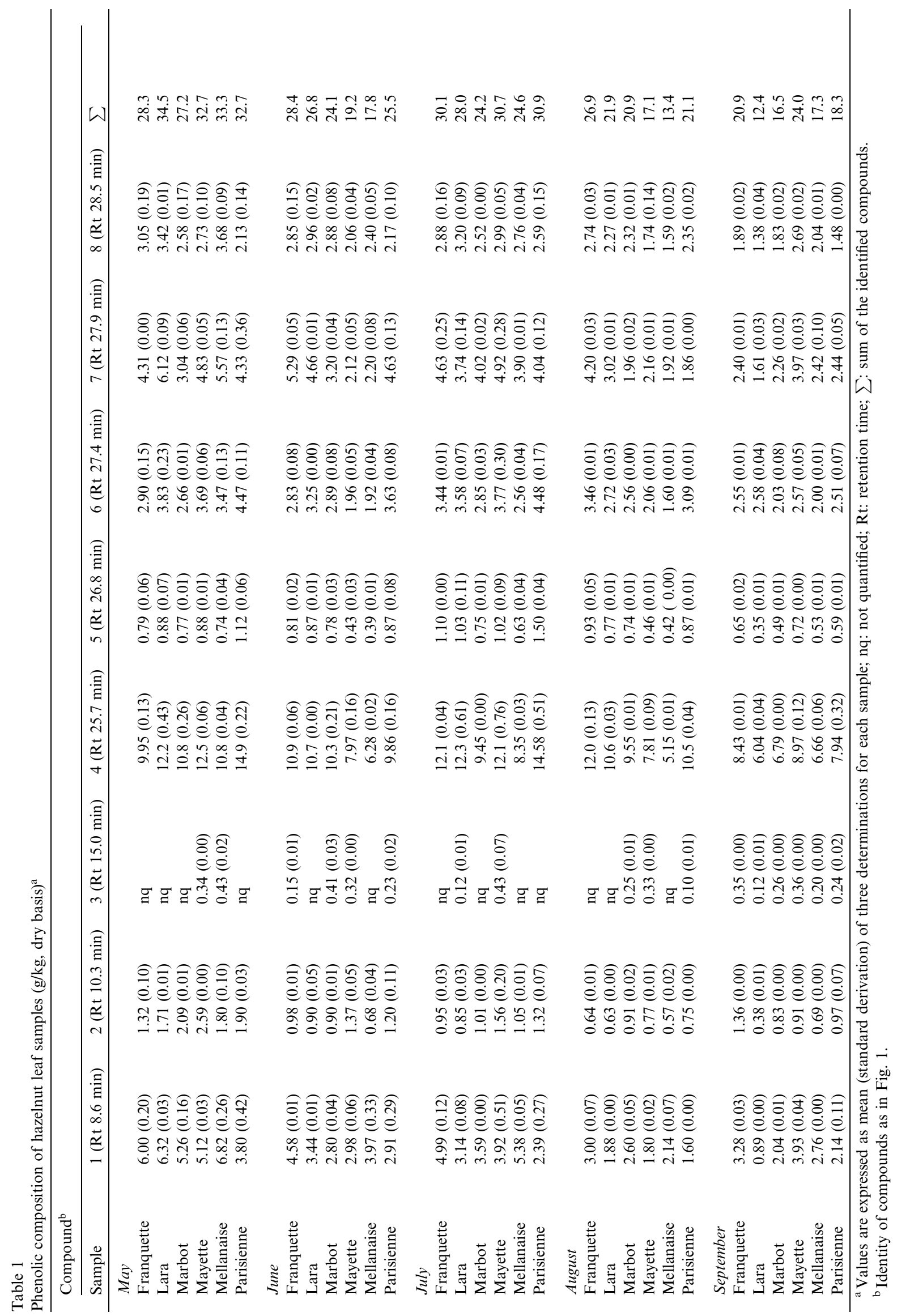




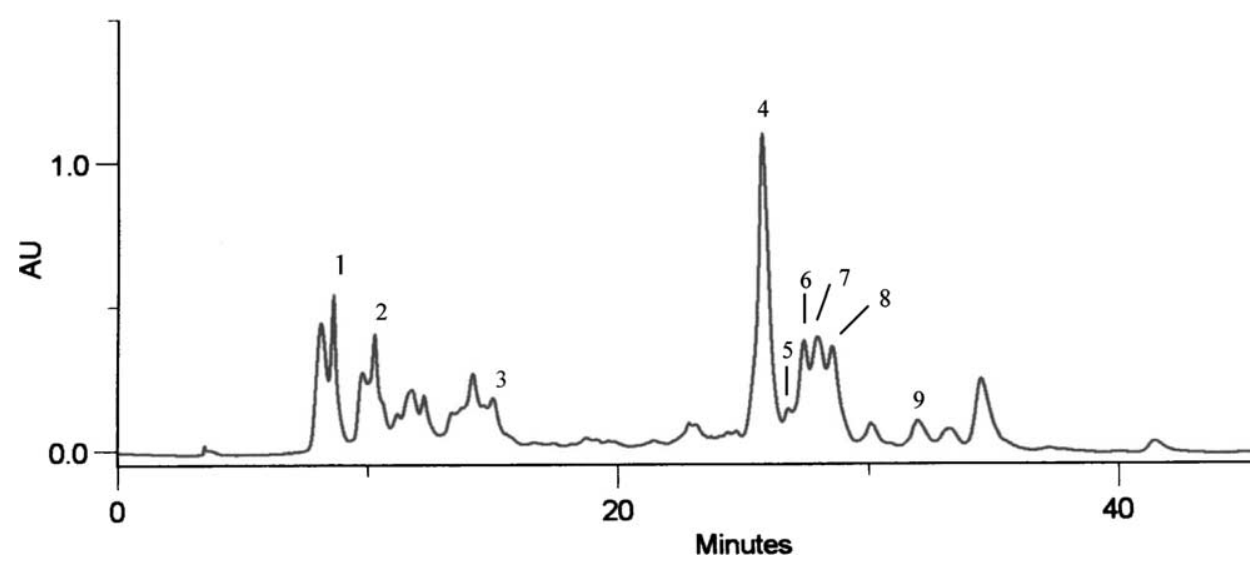

Fig. 1. HPLC/DAD walnut leaf phenolic profile. Detection at $320 \mathrm{~nm}$. 1: 3-caffeoylquinic; 2: 3-p-coumaroylquinic acid; 3: 4- $p$-coumaroylquinic acid; 4: quercetin 3-galactoside; 5: quercetin 3-pentoside derivative; 6: quercetin 3-arabinoside; 7: quercetin 3-xyloside; 8: quercetin 3-rhamnoside; 9: kaempferol 3-pentoside derivative.

$\mathrm{MS}^{2}$ study were done for these ions. The MS of 417.4 yielded a main ion at $m / z 284.9$, characteristic of kaempferol, suggesting the presence of a pentosyl kaempferol derivative. MS data from the two other compounds were not conclusive, but it seems that they are both derivatives of the same aglycone.

In general terms, all cultivars showed a common qualitative pattern, presenting seven identified phenolic compounds (Fig. 1): 3-caffeoylquinic, 3-p-coumaroylquinic and 4-p-coumaroylquinic acids, quercetin 3galactoside, quercetin 3-arabinoside, quercetin 3-xyloside, quercetin 3-rhamnoside and two partially identified compounds (quercetin 3-pentoside and kaempferol 3pentoside derivatives). As far as we know, 3-p-coumaroylquinic and 4-p-coumaroylquinic acids are reported in this species for the first time. Wichtl and Anton (1999) described the existence of other phenolic acids in walnut leaves, namely caffeic, ferulic, $p$-coumaric, $p$-hydroxyphenylacetic, gallic, salicylic, chlorogenic and neochlorogenic acids but, with the exception of 3-caffeoylquinic acid, those compounds were not detected in the present study. As no data concerning the cultivar and geographical origin of those samples were found, no correlation between the absence of those compounds and a given cultivar or origin can be inferred.

Chloroform was the solvent that extracted a small number of phenolic compounds. Besides, when comparing methanolic extraction and extraction with acidified water and purification via the SPE columns, it was possible to observe that both led to the same qualitative phenolic profile but, as a general rule, the extraction with acidified water, leads to an extract with a higher amount of phenolic compounds (data not shown). This last technique has the advantage of eliminating chlorophylls and allows the concentration of the extract in a shorter period of time. For quantification purposes all samples were subjected to this procedure.
As with the qualitative profile, all the analysed samples (all cultivars of all months) showed a common quantitative pattern if the results are analysed as percentages (Fig. 2). In this profile, quercetin 3-galactoside was the major flavonoidic compound $(32.5-48.9 \%)$ and 3-caffeoylquinic acid was the major phenolic acid (7.17-22.3\%) (Table 1). Quercetin 3-galactoside, quercetin 3-arabinoside, quercetin 3-rhamnoside, kaempferol and kaempferol 3-arabinoside have already been described in walnut leaf, but only qualitatively (Wichtl \& Anton, 1999) and no information is published about their ratios.

In Portugal, walnut leaves are traditionally collected at the end of spring and/or beginning of summer (Costa, 1975). So, a systematic analysis was carried out and samples were collected from May to September, in order to evaluate changes in the phenolic composition of the studied cultivars. Air and soil temperatures, solar radiation, wind and rain were registered every day during this period (data not shown). All cultivars presented slightly higher values of total phenolic compounds in May and July (Table 1). Mean values of phenolic acids, flavonoids and total phenolic contents seem to point to a decrease of compounds from May to June, an increase in July and a new decrease until September (Fig. 3). The first decrease might be related to the rapid development of the fruit in June, when most of the nutrients and photoassimilates are employed for fruit growth (Charlot $\&$ Germain, 1988). The hypothesis that flavonoid content is related to sun exposure, because of their function as sun filters, may possibly explain their rise in July, since this was the month with a higher value of solar radiation.

In conclusion, this study suggests that the technique herein described seems to be quite useful for analysis of walnut leaf phenolic compounds. This set of compounds, when examined qualitatively and quantitatively, define a fingerprint that may be suitable for assessing identity and quality. The nature of the cultivar 


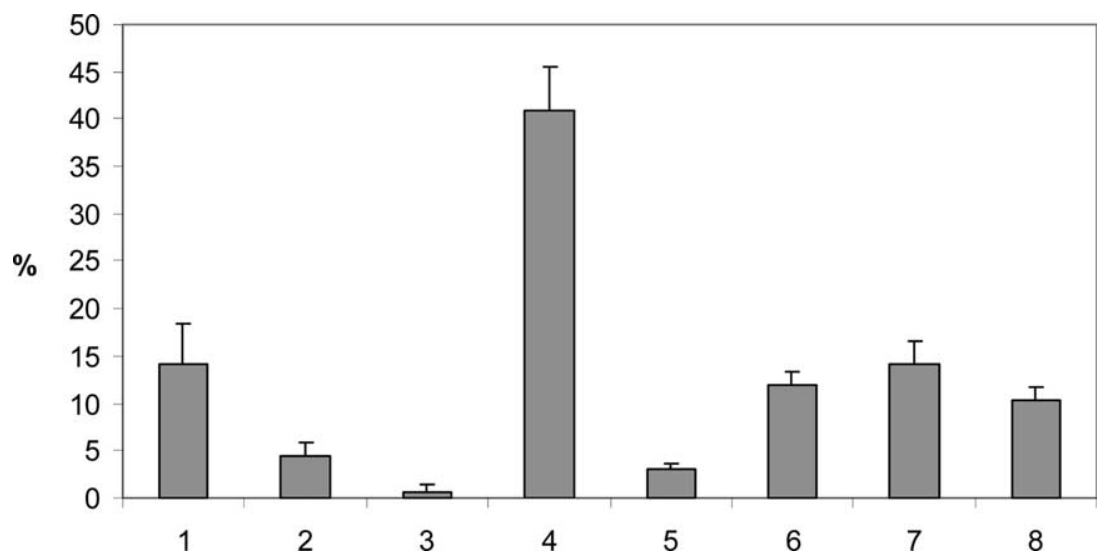

Fig. 2. Phenolic fingerprint of Lara, Franquette, Marbot, Mayette, Mellanaise and Parisienne cultivars. Results are the means of five samples collected for each cultivar. Identities of compounds are in Fig. 1.

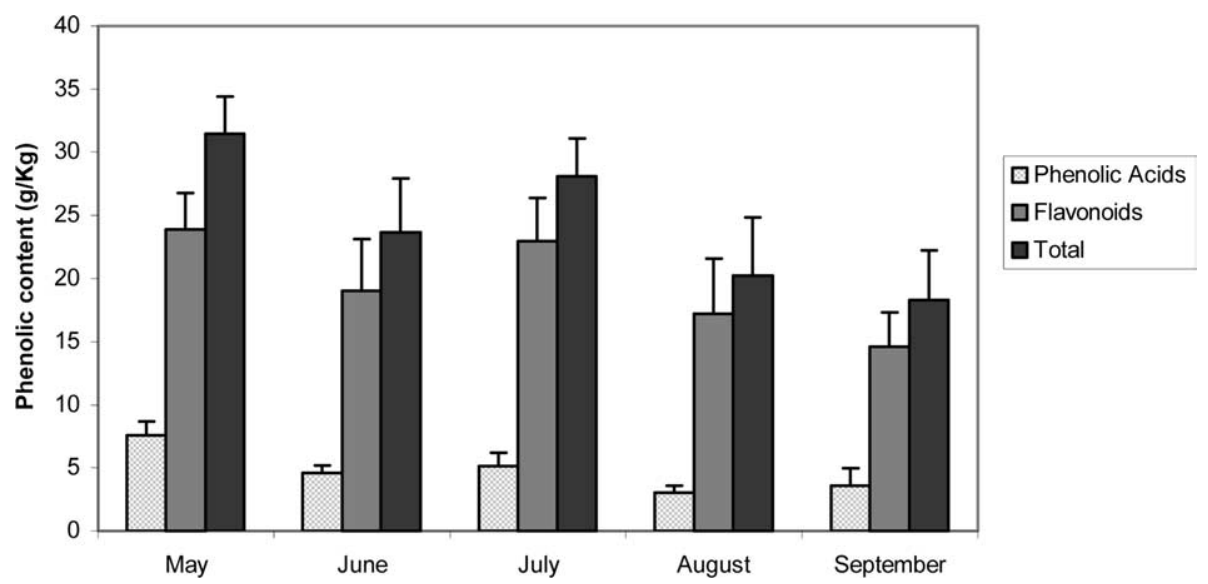

Fig. 3. Evolution of phenolic acids, flavonoids and total phenolic contents, between May and September 2003, of the walnut leaf samples. Results are the means of the six analysed cultivars and standard error bars are on the top of each column.

and the month of collection do not seem to influence the mentioned phenolic fingerprint of walnut leaves. Bearing in mind that flavonoids and phenolic acids have been the subject of several studies because of their antioxidant potential (Aquino et al., 2001; Sakakibara, Honda, Nakagawa, Ashida, \& Kanazawa, 2003; Valentão, 2002), the results obtained suggest that, for this purpose, walnut leaves should preferentially be collected in May or July, when phenolic content is higher. Besides, the phenolics present, mainly caffeic acid and quercetin derivatives, are excellent antioxidants since they bear the required structural characteristics for that, namely an ortho-dihydroxy group on an aromatic ring.

\section{Acknowledgements}

J.S. Amaral is grateful to Programa para o Desenvolvimento Educativo para Portugal (PRODEP III) for financial support.

\section{References}

Andrade, P., Ferreres, F., \& Amaral, M. T. (1997). Analysis of honey phenolic acids by HPLC, its application to honey botanical characterization. Journal of Liquid Chromatography and Related Technologies, 20, 2281-2288.

Andrade, P. B., Leitão, R., Seabra, R. M., Oliveira, M. B., \& Ferreira, M. A. (1997). 3,4-Dimethoxycinnamic acid levels as a tool for differentiation of Coffea canephora var. robusta and Coffea arabica. Food Chemistry, 61, 511-514.

Aquino, R., Morelli, S., Lauro, M. R., Abdo, S., Saija, A., \& Tomaino, A. (2001). Phenolic constituents and antioxidant activity of an extract of Anthurium versicolor leaves. Journal of Natural Products, 64, 1019-1023.

Areias, F. M., Valentão, P., Andrade, P. B., Ferreres, F., \& Seabra, R. M. (2001). Phenolic fingerprint of peppermint leaves. Food Chemistry, 73, 307-311.

Bruneton, J. (1993). Pharmacogosie, phytochimie, plantes médicinales. Paris: Tec.\&Doc.- Lavoisier (p. 348).

Charlot, G., Germain, E. (1988) Le Noyer Nouvelles techniques. Paris: Ctifl.

Chu, Y., Sun, J., Wu, X., \& Liu, R. H. (2002). Antioxidant and antiproliferative activities of common vegetables. Journal of Agricultural and Food Chemistry, 50, 6910-6916. 
Clifford, M. N., Johnston, K. L., Knight, S., \& Kuhnert, N. (2003). Hierarchical scheme for $\mathrm{LC}-\mathrm{MS}^{\mathrm{n}}$ identification of chorogenic acids. Journal of Agriculture and Food Chemistry, 51, 290-2911.

Costa, A. F. (1975). Farmacognosia (vol. I). Lisboa: Fundação Calouste Gulbenkian (pp. 986-989).

Gîrzu, M., Carnat, A., Privat, A.-M., Fiaplip, J., Carnat, A.-P., \& Lamaison, J.-L. (1998). Sedative effect of walnut leaf extract and juglone, an isolated constituent. Pharmaceutical Biology, 36(4), $280-286$.

Llorach, R., Gil-Izquierdo, A., Ferreres, F., \& Tomas-Barberan, F. A. (2003). HPLC-DAD-MS/MS ESI characterization of unusual highly glycosylated acylated flavonoids from cauliflower (Brassica oleracea L. var. botrytis) agroindustrial byproducts. Journal of Agriculture and Food Chemistry, 51, 3895-3899.

Ramos, R., Andrade, P. B., Seabra, R. M., Pereira, C., Ferreira, M. A., \& Faia, M. A. (1999). A preliminary study of non-coloured phenolics in wines of varietal white grapes (códega, gouveia and malvasia fina): Effects of grape variety, grape maturation and technology of winemaking. Food Chemistry, 67, 39-44.

Sakakibara, H., Honda, Y., Nakagawa, S., Ashida, H., \& Kanazawa, K. (2003). Simultaneous determination of all polyphenols in vegetables, fruits and teas. Journal of Agricultural and Food Chemistry, 51, 571-581.

Silva, B. M., Andrade, P. B., Valentão, P., Mendes, G. C., Seabra, R. M., \& Ferreira, M. A. (2000). Phenolic profile in the evaluation of commercial quince jellies authenticity. Food Chemistry, 71, 281285 .

Valentão, P., Fernandes, E., Carvalho, F., Andrade, P. B., Seabra, R. M., \& Bastos, M. L. (2002). Antioxidative properties of cardoon (Cynara carduncunlus L.) infusion against superoxide radical, hydroxyl radical, and hypochlorous acid. Journal of Agricultural and Food Chemistry, 50, 4989-4993.

Valnet, J. (1992). Phytothérapie Traitement des maladies par les plantes. Paris: Maloine (pp. 476-478).

Van Hellemont, J. (1986). Compendium de phytotherapie. Bruxelles: Association Pharmaceutique Belge (pp. 214-216).

Wichtl, M., \& Anton, R. (1999). Plantes thérapeutiques. Paris: Tec.\&Doc. (pp. 291-293).

Zafrilla, P., Ferreres, F., \& Tomas-Barberan, F. A. (2001). Effect of processing and storage on the antioxidant ellagic acid derivatives and flavonoids of red raspberry (Rubus idaeus) jams. Journal of Agricultural and Food Chemistry, 49, 3651-3655. 